\title{
Photoluminiscent Manganese Nanoparticles from Solid State Polyphosphazenes Organometallic Derivatives
}

\author{
Carlos Díaz, ${ }^{1,2}$ and María Luisa Valenzuela ${ }^{1}$
}

ERRATUM TO: JOURNAL OF INORGANIC

AND ORGANOMETALLIC POLYMERS AND

MATERIALS DOI 10.1007/s10904-006-9035-x

The submitted and accepted dates for this paper were inadvertently omitted. The dates are as follows: Submitted October 26, 2005; accepted December 15, 2006

The online version of the original article can be found at http:/ dx.doi.org/10.1007/s10904-006-9035-x

${ }^{1}$ Department of Chemistry, Faculty of Sciences, University of Chile, Casilla, 653, Santiago, Chile.

2 To whom correspondence should be addressed.

E-mail: cdiaz@uchile.cl 